\title{
FAST SHUTDOWN SYSTEM TESTS IN THE GEORGIA TECH RESEARCH REACTOR (U)
}

by

J.M. Wallace

Westinghouse Savannah River Company

Savannah River Site

Aiken, South Carolina 29808

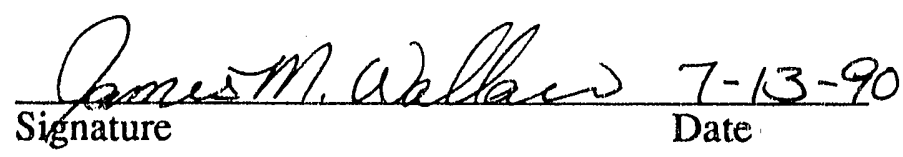

DISCLAIMER

\begin{abstract}
This report was prepared as an account of work sponsored by an agency of the United States Government. Neith ir the United Statu, Government nor any agency thereof, nor any of their employees, makes any warranty, express or implied, or assumes any legal liability or responsibility for the accuracy, completeness, or usefulness of any information, apparatus, product, or process disclosed, or represents that its use would not infringe privately owned rights. Reference herein to any specific commercial product, process, or service by trade name, trademark, manufacturer, or otherwise does not necessarily constitute or imply its endorsement, recommendation, or favoring by the United States Government or any agency thereof. The views and opinions of authors expressed herein do not necessarily state or reflect those of the United States Government or any agency thereof.
\end{abstract}

The information contained in this article was developed during the course of work under Contract No. DE-AC09-89SR18035 with the U.S. Department of Energy. By acceptance of this paper, the publisher and/or recipient acknowledges the U.S. Government's right to retain a non-exclusive, royalty-free license in and to any copyright covering this paper along with the right to reproduce, and to authorize others to reproduce all or part of the copyrighted paper.

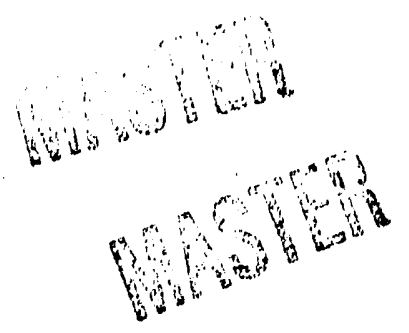


REACTOR TECHNOLOGY

WSRC-TR-90-42-019

FAST SHUTDOWN SYSTEM TESTS

in the

GEORGIA TECH RESEARCH REACTOR (U)

by:

J.M. Wallace

Issued: $3-16-90$

APPROVALS

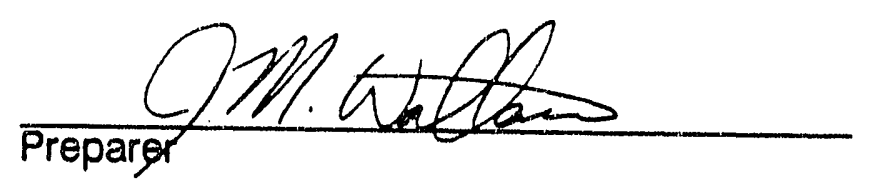

Technical Reviewer

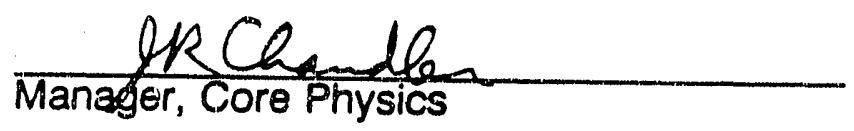

FD anton

Manager, Reactor Operational Analysis
Date: $3-14-90$

Date: $3-15-90$

Date: $3-16-90$

Date: $3-16-90$ 


\author{
FAST SHUTDOWN SYSTEM TESTS \\ IN THE \\ GEORGIA TECH RESEARCH REACTOR (U) \\ by \\ J.M. Wallace \\ Westinghouse Savannah River Company \\ Savannah River Site \\ Aiken, South Carolina 29808
}

\title{
INTRODUCTION
}

The Fast Shutdown System (FSS) is a new safety system design concept being considered for installation in the Savannah River Site (SRS) production reactors. This system is expected to mitigate the consequences of a Design Basis Loss of Coolant Accident, and therefore allow higher operational power levels. A test of this system in the Georgia Tech Research Reactor is proposed to demonstrate the efficacy of this concept.

The Fast Shutdown System consists of a pressure sensing circuit which actuates an explosive valve thereby injecting He-3 gas from a high pressure cylinder into a hollow rod in the reactor (Figure 1). The system to be tested in the Georgia Tech Research Reactor (GTRR) will be similar, consisting of an electronic actuation system, an explosive valve, a high pressure He-3 gas cylinder, and an FSS rod modified to fit the GTRR geometry (Figure 2). The modified FSS rod will be installed in core position V19 using a specially designed dummy fuel assembly. The rod will extend from the bottom of the core to just above the lower shield plug. Tubing will connect the rod to the explosive valve and gas cylinder placed on top of the top shield. Neutron detectors will be located in experimental ports V21 and V22. Pressure sensors will be located at the top of the rod and near the gas cylinder.

Three tests will be conducted at full power (5MW) and one at low power (100kw). Two full power tests will be conducted with the FSS rod backfilled with one (1) atmosphere of He-4, and one with the rod evacuated. The low power test will be conducted with the FSS rod evacuated. Neutron flux and pressure data will be collected with an independent data acquisition system (DAS).

\section{SUMMARY}

Safety issues associated with the performance of the Fast Shutdown System experiments are addressed in this report. The credible accident scenarios were analyzed using worst case scenarios to demonstrate that no signficant nuclear or personnel safety hazards would result from the performance of the proposed experiments.

\section{DISCUSSION AND RESULTS}

\section{Introduction}

At one time, a prototype Fast Shutdown System Test was planned using three full length rods in the Savannah River Site K-Reactor. However, schedule and resource limitations made it prudent to pursue offsite facilities for design testing purposes. Yet, before this decision was made, a complete safety analysis review was conducted as part of a Test Authorization Document for the test. This and supporting safety analysis studies were reviewed for applicability to the FSS test 
Figure 1

Fast-Acting SCRAM System

Conceptual Schematic

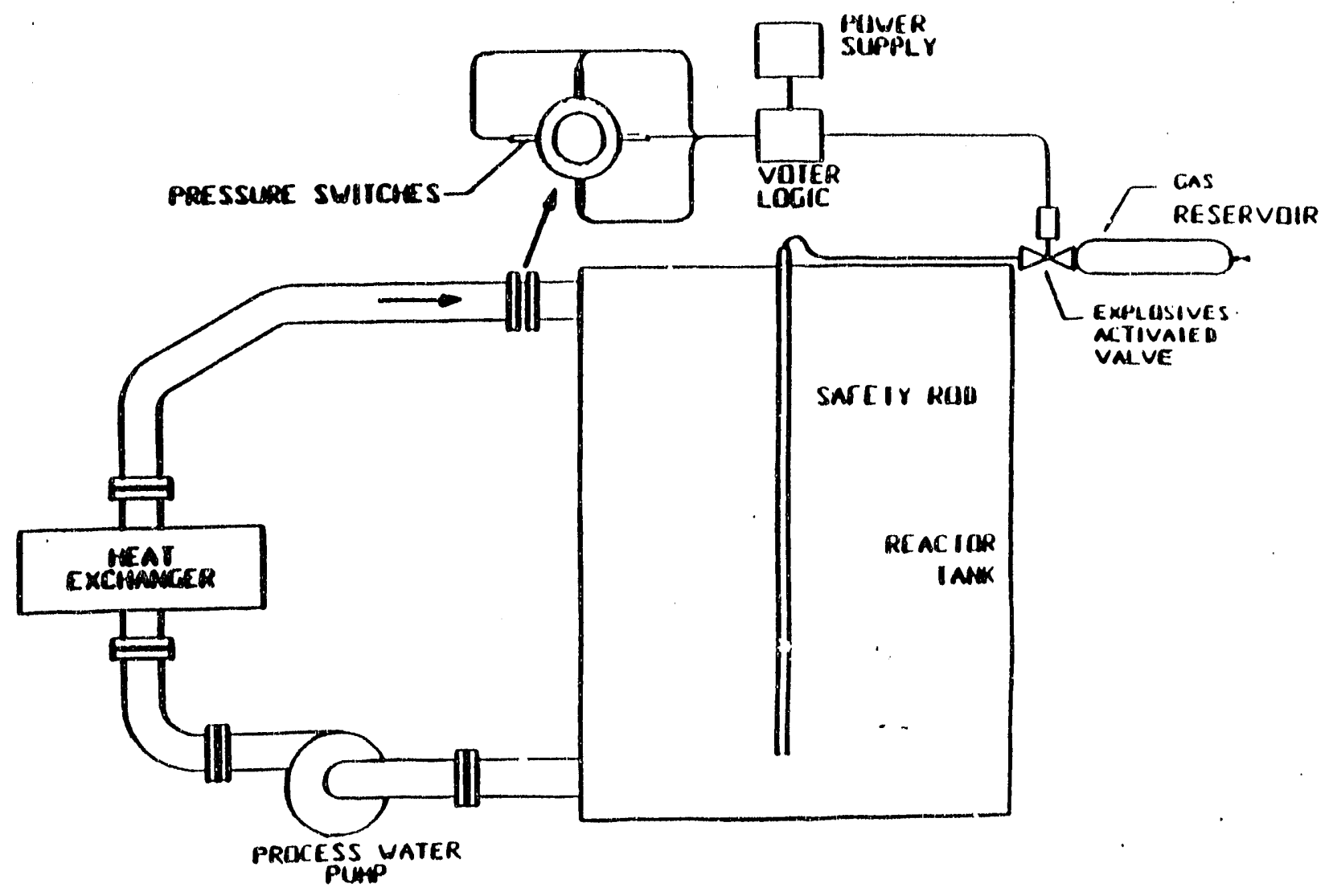


Figure 2

Fast Shutdown System Test Schematic

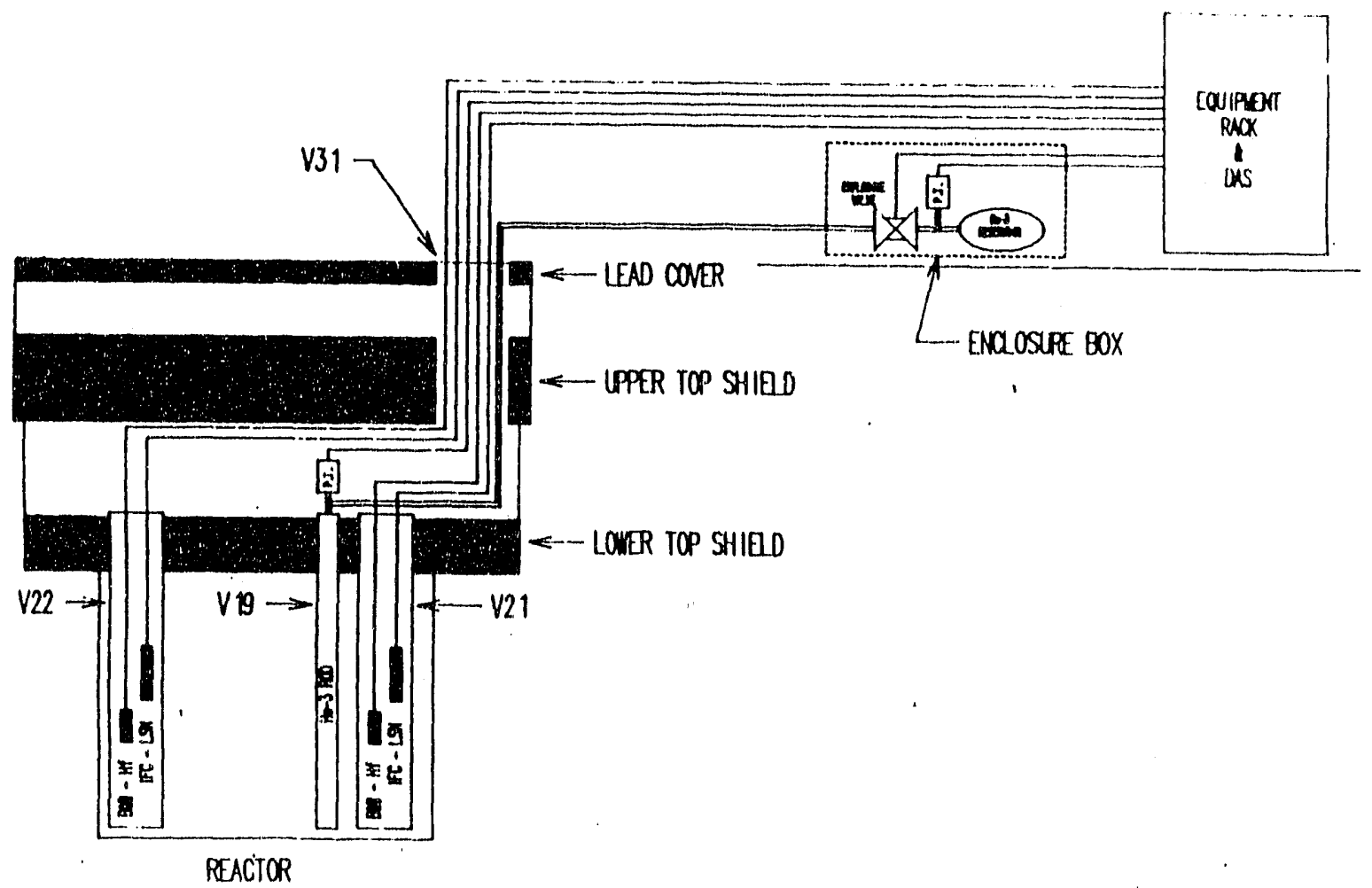


proposed for the GTRR. In addition, independent safety analyses were performed specifically for the Georgia Tech Research Reactor design.

Since the Fast Shutdown System tests involve reactivity changes in the GTRR core, sophisticated reactor analysis methods were employed to analyze the safety questions. These methods and the models are discussed below. Then, the accident scenarios themselves and the pertinent results are reviewed. The accidents given analytical consideration in this report include:

1. Loss of FSS Rod Integrity

2. Loss of He-3 After Injection

3. Tritium Release.

Also included is a discussion of radiation shielding considerations in support of the modified lower shield plug designs.

\section{Reactor Analysis Methods}

The reactor analysis methods used for the GTRR are identical to those used for everyday reactor analysis of the SRS reactors. Fortunately, the two reactor core designs are very similar. Both reactor designs use HEU-Aluminum clad fuel and are heavy water moderated and cooled. Both reactors operate at nominal thermal neutron fluxes of $1 \times 10^{14}$ neutrons $/ \mathrm{cm}^{2}-\mathrm{sec}$ with a fastto-thermal flux ratio which is within a factor of two. The lattice pattern of both reactor types is triangular with a 7" pitch for the SRS reactors and a 6" pitch for the GTRR. This great similarity between the two core designs made it possible to use standard and widely used SRS reactor analysis tools to perform the analyses for the Fast Shutdown System tests in the GTRR. Each of these tools will be briefly discussed in the following paragraphs.

The first step in virtually any reactor analysis is to generate appropriate cross-section sets for the problem. The SRS Generalized Lattice Analysis Subsystem Computer Code (GLASS), which is the fundamental lattice physics tool in use at Savannah River, was utilized for this task. GLASS is an infinite lattice code which solves the multigroup neutron transport equation via the collision probability method in order to generate hexagonal cell averaged macroscopic crosssections. Multiplication factor, buckling, and depletion calculations may also be performed with GLASS; however, the primary result is a cross-section set which may be utilized in other finite reactor calculations.

Static finite reactor calculations were performed for the GTRR using the computer code GRIMHX, a 3D (actually Hex-Z) diffusion theory code. GRIMHX solves the multigroup diffusion equations utilizing the cell averaged macroscopic cross-sections generated with GLASS. The numerical scheme employed in GRIMHX is a standard finite differencing technique with overrelaxation acceleration methods. This code is widely utilized at SRS for routine reactivity, power distribution, and spatially dependent static reactor analysis.

Two different SRS computer codes have been utilized to perform. time dependent reactor analysis for the Fast Shutdown System tests in the GTRR. Version 3 of the Accident Analysis computer code (AA3) is a reactor accident analysis tool which utilizes the point reactor kinetics equations to model the transient neutron behavior. Also, various thermal-hydraulic relationships are used to model the engineering aspects of reactor transients. Nuclear feedback effects are included. This code is widely used at Savannah River Site for the performance of routine accident analyses and to demonstrate that operational requirements of the reactor are satisfied. The other transient analysis code used for the GTRR tests is TRIMHX, a Hex-Z geometry, time dependent diffusion theory code. TRIMHX utilizes numerical methods similar to those in GRIMHX, and is used for problems in which space-time reactor analysis is required. 


\section{Reactor Analysis Models}

The GLASS model used for generating the cross-section sets for the Georgia Tech fuel utilized a 37-hexagon repeating lattice pattern. This pattern consisted of a center cell containing an FSS rod, surrounded by two rings of fuel, surrounded by a ring of $\mathrm{D}_{2} \mathrm{O}$ moderator. The fuel cell itself, consisting of thin curved fuel plates arranged into a rectangular assembly, was not modelled explicitly. However, theoretical arguments suggest that resonance self-shielding in U-238 is not as important for highly enriched uranium fuel and therefore the geometrical representation is not critical. The validity of this approach was substantiated by constructing two geometrical representations of the Georgia Tech fuel and making material buckling and multiplication factor comparisons. A heterogeneous and a homogeneous model were selected for comparison (Figure 3). The heterogeneous model consisted of three annular rings of fuel in which material quantities, fuel and clad thicknesses, and interstitial coolant channel thicknesses were conserved. The homogeneous model consisted of a single circular homogenized fuel region in the center of the hexagon in which the total area of the fuel assembly and material quantities were conserved. Crosssection sets from these two models were compared by performing two group material buckling and multiplication factor calculations. The two group cross-section sets, material bucklings, and multiplication factors are shown in Table 1. The results of these calculations illustrate the insensitivity of integral parameters, such as the material buckling and the multiplication factor, to the geometric representation and resulting cross-section sets. Therefore, these results justify the use of the annular model of the Georgia Tech fuel.

The three-dimension GRIMHX model of the GTRR contains 217 hexagonal cells. For a standard core, the center cell and the first two rings contain fuel. The next four rings ( 2 feet) compose the reflector region, and the last ring is poison. Axially, the core region is represented by four layers ( 2 feet) covered on the top and bottom by four layers of $\mathrm{D}_{2} \mathrm{O}$ reflector ( 2 feet each). This model is modified as necessary to analyze specific core configurations. Experimental ports are not modelled except as necessary. Shim-safety blades are also not modelled. The primary purpose of this model is to determine reactivity changes, for different locations for experimental equipment, and for possible accident events.

Version 3 of the SRS Accident Analysis Code (AA3) was used to model the accident power transients considered for the Fast Shutdown System Tests in the GTRR. The basic SRS model was modified to reflect the different channel lengths and sizes, the number of assemblies, and various other thermal-hydraulic differences. Although the code has the capability to model the external loop, this feature was turned off, due to the very short nature of the transients of interest. Also, some adjustments to the bulk moderator region model of the SRS reactors were made to more closely simulate the relector region of the Georgia Tech reactor. Although explicit modelling of this region was not possible, the short nature of the transients considered makes a discrete reflector region model unimportant.

The TRIMHX code utilizes the same spatial model employed by the static GRIMHX code. However, for time-dependent analyses, the two-dimensional model is used and axial leakage is included as an input parameter. The primary use of this code is for prediction of the space-time response of the core to the Fast Shutdown System injection of He-3. Therefore, the model is composed of a 17-element core, with the central fuel cell empty and V19 occupied by the FSS rod. Vertical experimental ports V21 and V22 are also modelled explicitly since these tubes will contain the neutron detection equipment. The transient is modelled by a time varying adjustment to the cross-section set for the perturbed cell, in this case the FSS rod in V19. The cross-section adjustments are determined with GLASS and are fitted to an equation for use in TRIMHX. The curve shown in Figure 4 is an estimate of the expected He-3 injec:ion transient. This curve was determined using an exponentially varying thermal capture cross-section in cell V19 of a shape similar to the one used for FSS analyses in SRS reacto. $\cdots$ A more detailed prediction will be made 
later based on the results of cold laboratory injection tests for the system to be tested in the Georgia Tech reactor. These laboratory tests will provide exact pressure versus time data which can be converted to concentration of He-3 versus ime data. This will be used in GLASS to generate the time dependent cross-sections which will be fit to an equation for use in TRIMHX.

Table 1

GEOMETRIC FUEL MODEL COMPARISONS

\section{HETEROGENEOUS ANNULAR MODEL}

Group

Groun Cross-Sections

Capture $(1 / \mathrm{cm})$ Fission $(1 / \mathrm{cm}) \quad \mathrm{Nu} \times$ Fission $(1 / \mathrm{cm})$

$1 \quad 0.405681 \mathrm{E}-3$

$0.520596 \mathrm{E}-3$

$0.126920 \mathrm{E}-2$

$0.471015 \mathrm{E}-2$

$0.134869 \mathrm{E}-1$

$0.328164 \mathrm{E}-1$

Transfer Matrix

Initial Group

1

2

Final Group $1(1 / \mathrm{cm})$

Einal Group $2(1 / \mathrm{cm})$

0.286094

$0.603580 \mathrm{E}-02$

0.0

0.357052

Material Buckling $=0.264962 \mathrm{E}-02$

Multiplication Factor $=1.243$

HOMOGENEOUS ANNULAR MODEL

Group

Group Cross-Sections

Capture $(1 / \mathrm{cm})$ Fission $(1 / \mathrm{cm}) \quad \mathrm{Nu} \times$ _Fission $(1 / \mathrm{cm})$

$1 \quad 0.384536 \mathrm{E}-3$

$2 \quad 0.390046 \mathrm{E}-2$

$0.491402 \mathrm{E}-3$

$0.119973 \mathrm{E}-2$

$0.116075 \mathrm{E}-1$

$0.282434 \mathrm{E}-1$

Transfer Matrix

Initial Group

Final Group $1(1 / \mathrm{cm})$ Final Group $2(1 / \mathrm{cm})$

1
0.284361
$0.579305 \mathrm{E}-02$
0.0
0.377734

Material Buckling $=0.252573 \mathrm{E}-02$

Multiplication Factor $=1.241$ 
Figure 3

Reactor Analysis Models

\section{Heterogeneous Model}

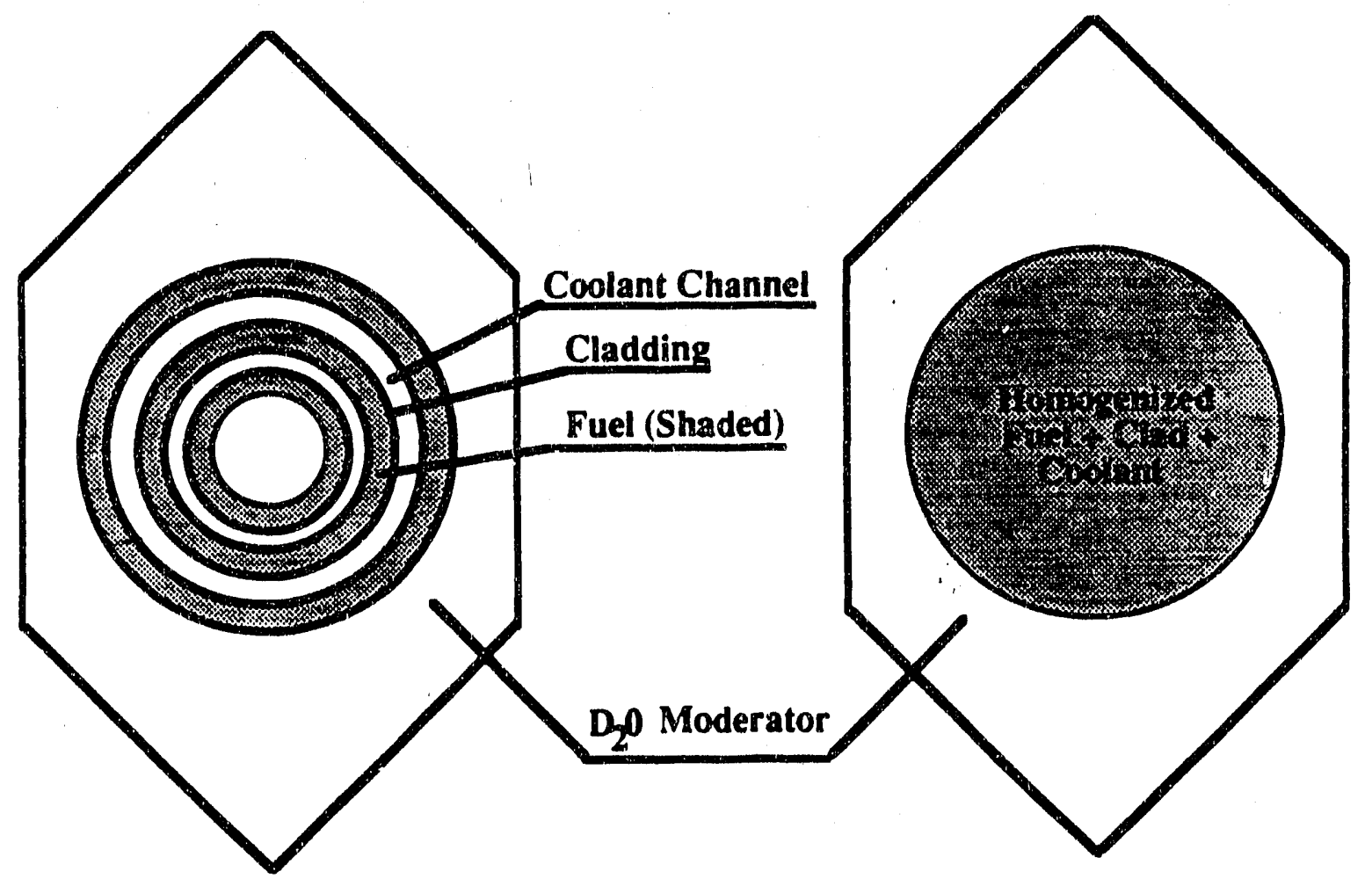


Figure 4

FSS Transient

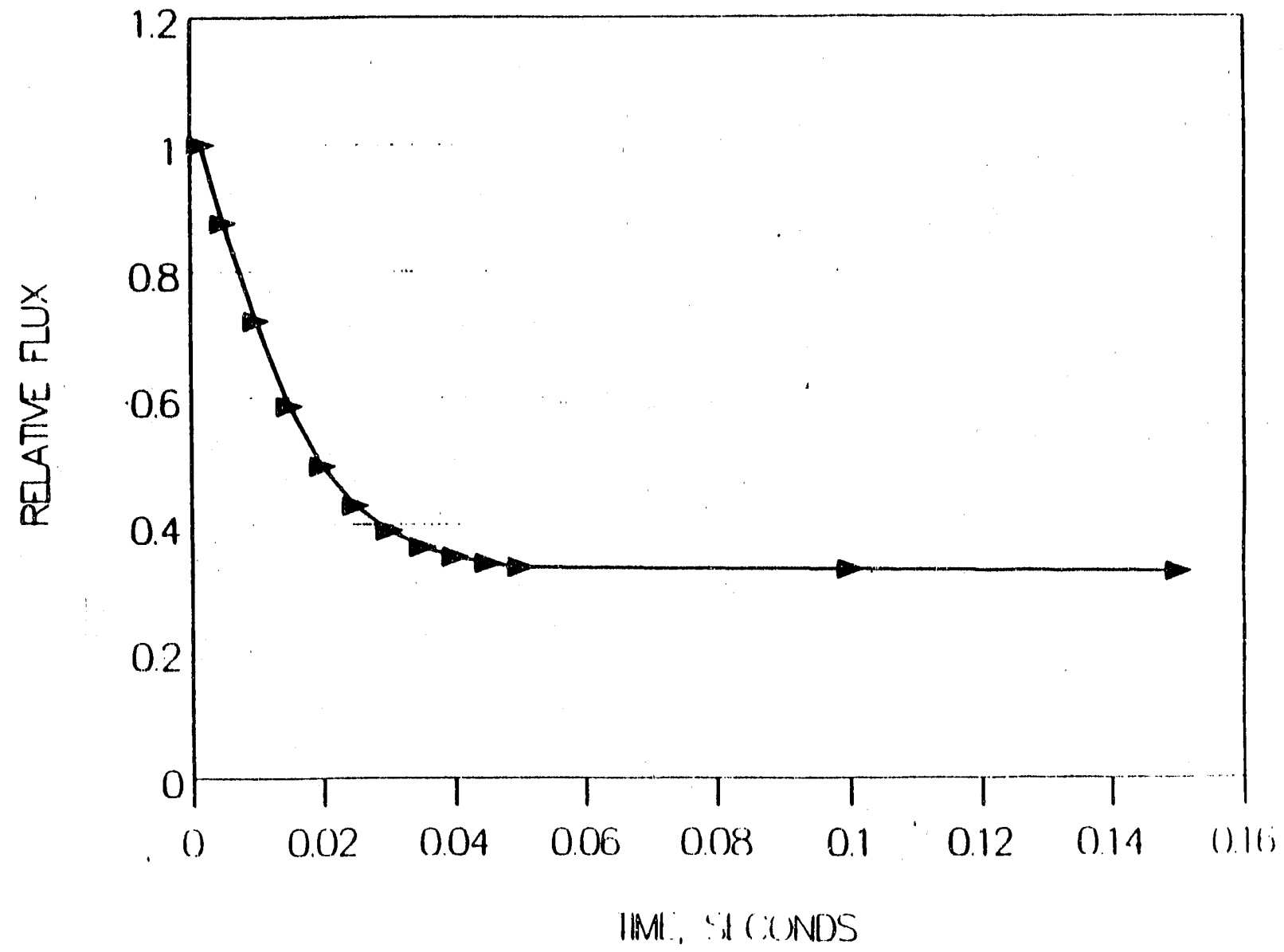




\section{ACCIDENT SCENARIOS}

\section{Loss of FSS Rod Integrity}

This effect was quantified using the 3D GRIMHX model discussed above. Two static $\mathrm{K}_{\text {eff }}$ calculations were performed; one calculationn had an evacuated FSS rod in core position V19, and the other had $\mathrm{a}_{2} \mathrm{O}$ filled FSS rod in core position V19. The difference, along with the base case $\mathrm{K}_{\mathrm{eff}}$, gave the reported $0.017 \% \Delta \mathrm{k} / \mathrm{k}$ reactivity worth.

This methodology was checked using the experimentally determined reactivity worth of experimental ports reported in the SAR 1 . The reactivity worth data for vertical port V21 was chosen for checking the methodology since V21 is adjacent to the FSS rod position, V19. Also, experimental port $\mathrm{V} 21$ is in the same orientation (i.e., vertical) and occupies the same axial position relative to the core. V21 is a $2-5 / 8$ " diameter thimble and liner which displaces $\mathrm{D}_{2} \mathrm{O}$ when installf For V21, the SAR experimentally determined value of $0.37 \% \Delta \mathrm{k} / \mathrm{k}$ represents the difference between the thimble and liner installed empty (containing only air) and the thimble and liner removed from the reactor. Cross-section sets with and without V21 installed were generated using a symmetrical 13-element, 142 gm U-235/element core as described in the SAR ${ }^{1}$. These crosssection sets were then used in a symmetrical 13-element 3D GRIMIIX model to calculate the reactivity worth of V21. The calculated value was $0.43 \% \Delta \mathrm{k} / \mathrm{k}$. This value is relatively close and conservative compared to the experimentally determined value of $0.37 \% \Delta \mathrm{k} / \mathrm{k}$.

Therefore, the loss of integrity of an evacuated FSS rod while at power would result in a reactivity increase of approximately $0.017 \% \Delta \mathrm{k} / \mathrm{k}$ or about 2 -cents worth. As a result, reactor power would increase until the reactivity was again balanced by temperature feedback effects. However, given that the temperature coefficient reported in the Safety Analysis Report is $-0.0232 \% \Delta \mathrm{k} / \mathrm{k}$ per ${ }^{\circ} \mathrm{C}$, an FSS rod loss of integrity event would result in less than a one degree Celsuis increase in coolant temperature. ${ }^{1}$ Ergo, no serious consequences would result from this event.

Another consideration relating to the loss of FSS rod integrity involves the escape of gas (either $\mathrm{He}-3$ or $\mathrm{He}-4$ ) into the moderator from a failed rod. In both cases the gas would be expected to leak into the moderator space, thereby forming voids or gas bubbles which would be swept out of the core by the combined effects of buoyancy and the hydraulic action of the moderator. For the $\mathrm{He}-4$ case, this event is postulated to occur at power with the rod filled with one atmosphere of $\mathrm{He}-4$, and during the period before the injection test has oscurred. In this case, leakage of $\mathrm{He}-4$ into the moderator would be displaced by $\mathrm{D}_{2} \mathrm{O}$ in the rod, the positive reactivity effects of which were analyzed above. The void produced in the moderator space surrounding the rod is assumed to have the same reactivity worth as the void inside the FSS rod. Therefore, taken alone, the gas would have a negative effect while in the core region followed by a corresponding positive effect upon departure. The net effect is bounded by the above considered rod failure event in which an evacuated FSS rod is replaced with a $\mathrm{D}_{2} \mathrm{O}$ filled rod.

In the case in which He-3 occupies the rod upon failure, the event is postulated to occur at power during the period between the He-3 injection and the reactor being shutdown (a maximum practical time of one second). The He-3 would escape into the moderator space surrounding the rod and subsequently leave the core region until the gas pressure in the rod equilibrated with the moderator pressure. Then, the remaining $\mathrm{He}-3$ could be displaced with $\mathrm{D}_{2} \mathrm{O}$ depending on the type of failure. The He-3 gas escaping the rod would reduce the concentration in the rod and therefore reduce its negative reactivity effects. This event taken alone is bounded by the following analysis of the injection/ejection accident. The subsequent filling of the rod with $\mathrm{D}_{2} \mathrm{O}$ would add the $0.017 \% \Delta \mathrm{k} / \mathrm{k}$ effect to the $1.5 \% \Delta \mathrm{k} / \mathrm{k}$ effect of the He-3 itself (discussed below). This would result in a small additional power increase which is still essentially the same as that analyzed below. 


\section{Loss of Helium-3 Gas After Injection}

This event was analyzed with the AA3 code described above. Reactivity versus time data was input into the code to drive the transient. The reactivity worth of the He-3 filled FSS rod in core position V19 in a 17-element core was calculated with a 3D GRIMHX model. Two $\mathrm{K}_{\mathrm{eff}}$ cases were run; one with the FSS rod evacuated, and a second with the rod filled with $1.1 \mathrm{mg} / \mathrm{ml}$ of $\mathrm{He}-3$ (130 psia). The resultant calculated reactivity worth of the rod was $1.5 \% \Delta \mathrm{k} / \mathrm{k}$.

The postulated accident scenario is a full injection of the He-3 gas, followed by a complete rod failure external to the core resulting in ejection of all of the gas out of the rod. The injection time selected was 50 milliseconds, which is consistent with the system design and previous injection test data on similar systems. The time period between the injection and the rod failure (deiay time) was varied in order to determine the effects of overshoot from temperature feedback. The complete ejection of the gas was assumed to occur in 50 milliseconds.

The temperature coefficient value reported in the SAR for the 5MW, 16-element clean core at $45^{\circ} \mathrm{C}$ is $-0.0232 \% /{ }^{\circ} \mathrm{C}$. This is a calculated value. ${ }^{1} \mathrm{~A}$ calculated value was reported since it produced a smaller temperature coefficient than the experimentally determined value, that is the 13element core experimental value was $-0.0535 \% / \mathrm{C}$ versus the calculated value of $-0.0383 \% / \mathrm{C}$. However, since a larger temperature coefficient can result in a larger power overshoot for the considered transient, a value of $-0.0383 \% \% \mathrm{C}$ was selected. This is a biased value accounting for the difference in calculated and experimental values for the 13-element core. This was considered a reasonable value for the purposes of this analysis. In addition, several cases were run with different temperature coefficients. Those results are included in Table 2.

The fuel temperature coefficient was chosen to be zero in the AA3 model due to the higilly enriched nature of the Georgia Tech fuel design. However, since the fuel temperature coefficient has a more prompt effect on power transients, analyses were performed to ensure a non-positive value. GLASS calculations were performed on the Georgia Tech fuel model at temperatures $71^{\circ} \mathrm{C}$, $90^{\circ} \mathrm{C}$, and $200^{\circ} \mathrm{C}$. The results verified that the Doppler effect was very small and negative. For academic interest, these calculations were repeated with the U- 238 content artificially removed from the Georgia Tech fuel. The results produced a smaller, but still negative effect, indicating a corresponding increase in resonance captures as well as resonance fissions with an increase in temperature. The results from these analyses are shown in Table 3.

Since the AA3 code uses the point-kinetics equations, the spatial effects of this accident could not be determined explicitly by this code alone. Theoretically, since the reactor is small and $\mathrm{D}_{2} \mathrm{O}$ moderated, the spatial effects for this type of accident scenario are expected to be very small. Nevertheless, in order to be conservative, the spatial effects of this accident scenario were analyzed explicitly using the adiabatic approximation. A linear He-3 concentration-vs-time injection/ejection profile was assumed, based on experimental data from injection tests. Then, cross-section sets were generated for a discrete set of $\mathrm{He}-3$ concentrations using GLASS. These cross-section sets were input into a corresponding set of 2D-GRIMHX calculations in order to generate a $\mathrm{K}_{\mathrm{eff}}$ value and a power profile for each He-3 concentration. The axial leakage of the

$0 \mathrm{mg} / \mathrm{cc} \mathrm{He}-3$ concentration base case was adjusted to get a critical core. This data was combined to generate a $K_{\text {eff }}$-vs-time table for use in AA3 to generate total power-vs-time for the accident. The AA3 output was combined with the normalized 2D-GRIMHIX power profiles to provide the spacetime behavior of the core. This method has been shown to give values within approximately $1 \%$ of a similar time-dependent diffusion theory treatment of Fast Shutdown System transients. The results given in Table 4 are for the $50 \mathrm{~ms}$ delay time case. It should be noted from these results that the space-time effects in the adiabatic approximation are present only during the perturbation (injection and escape of $\mathrm{He}-3$ ). Since the final condition (no He-3) is the same as the initial 
condition, all relative powers beyond this time are identical, thereby resulting in no assembly power exceeding the corresponding global power after $150 \mathrm{msec}$. Therefore, since the peak power necessarily lags the perturbation, the accident cases are adequately represented by the AA3 code alone.

The AA3 calculations were run for three seconds even though the reactor protection system would be expected to end the transient much. sooner. Figure 5 shows the 50 millisecond delay time transient case, and is typical of the others.

Gross fuel element failure and concomitant fission product release will not occur unless there is departure from nucleate boiling (DNB). DNB will not occur at power levels up to 11.5 $\mathrm{MW}$ with the coolant outlet temperature and coolant flow at their respective limiting safety system settings for forced cosvection mode operation (Tech.Specs.). Therefore, neither the conservative case power overshoot (103\%) nor the extreme case power overshoot $(125 \%)$ would result in claduing failure and concomitant release of radioactive material which could lead to doses in excess of the limits set forth in 10CFR Part 20.

\section{Tritium Release}

The He-3 used for the Fast Shutdown System is a by-product of the tritium production process at the Savannah River Site. As a result, the He-3 retains some of the tritium as ail impurity. Also, the ${ }^{3} \mathrm{He}(\mathrm{n}, \mathrm{p})^{3} \mathrm{H}$ reaction will produce tritium while the $\mathrm{He}-3$ gas is in a neutron flux in the core. The personnel safety and regulatory release consequences associated with the tritium are addressed below.

Due to the size of the DOT approved container to be used for He-3 shipmatit, a maximum of 10 Curies of tritium impurity may be present. The amount of tritium produced in an FSS rod during a test in the GTRR was calculated under the following assumptions:

- Ten minute exposure period

- $\quad 1.1 \times 10^{14}$ neutrons $/ \mathrm{cm}^{2}$ per sec peak flux

- Decay of the flux driven by the FSS alone

- No flux depression in the rod

- The entire volume of the rod in the core and reflector exposed to peak flux.

The result was an estimated tritium production of $<1$ millicurie per high power test. This result is consistent with previous independent calculations performed to determine the amount of tritium production from a Fast Shutdown System test in SRS reactors.

The regulations governing the release of tritium to the envir nment are found in Title 10 Part 20 of the Code of Federal Regulations. ${ }^{3}$ The limit for release in air is given as a concentration of $2 \times 10^{-7} \mu \mathrm{Ci} / \mathrm{ml}$, which may be obtained by averaging release quantitites over a period of not greater than one year. The release of the maximum 10 Curies of tritium associated with the FSS tests averaged over a ten week period, assuming a stack flow rate of $34,000 \mathrm{cfm},{ }^{1}$ would not exceed the annual limits set forth in these regulations. 
The Technical Specification limit on tritium release in air is $2925 \mu \mathrm{Ci} / \mathrm{sec}$, at which point the containment is isolated. Therefore, any inadvertent release would be limited by the containment isolation system.

The shipping container will be DOT approved for the shipment of high pressure gas. Also, the test equipment has been or will be designed and pressure tested to withstand the pressures associated with the FSS tests. In addition, leak tests of the test equipment will be performed after installation and prior to FSS testing. Also, helium detection equipment will be available to monitor for potential leakage of the containers and apparatus.

\section{Shielding Considerations}

Special lower shield plugs will be designed for the FSS rod and neutron detectors. The rod will be placed in core position V19 and has an aluminum inset at the top of the rod sufficient to reduce the gamma field by a factor of 10,000 . The neutron detectors will be placed in core positions V21 and V22 (Figure 2), with the detector leads passing through the shield plugs in a manner to minimize streaming effects. The remainder of the special lower shield plugs will contain materials identical to standard lower shield plugs or of equivalent shielding capability.

The tubing that connects the FSS rod and the gas cylinder, along with the detector leads, will be routed in the space between the upper and lower shield plugs over to position V31. Position V31 is above one of the shim-safety blade drives and is not directly above the core. The upper shield plug over this location will be removed, and the tubing and detector leads will be routed up through this opening to the gas cylinder and data acquisition system atop the reactor. Personnel

will not be required to be over this opening during react operation; therefore, additional shielding is not expected to be required. However, temporary shi . 'ng may be used at this opening as deemed necessary during pre-test reactor start-up.

\section{CONCLUSIONS}

The safety consequences of all of the credible accidents considered within this report are not significant. The loss of FSS rod integrity accident while at full power would result in less than a one degree Celsuius increase in coolant temperature. The loss of He-3 gas after injection while at full power would conservatively result in a $3 \%$ overshoot in power. The tritium release potential is within the requirements of Title 10, Part 20 of the Code of Federal Regulations. Therefore, no serious consequences would result from the performance of these experiments.

\section{REFERENCES}

1. W.W. Graham,III and D.M. Walker, Safety Analysis Report for the SMW Georgia Tech Research Reactor, Technical Report No. GT-NE-7, December 1967.

2. U.S. Nuclear Regulatory Commission, Title 10, Code of Federal Regulations, Part 50: Licensing of Production and Utilization Facilities, Washington, D.C. January 1, 1987.

3. U.S. Nuclear Regulatory Commission, Title 10, Code of Federal Regulations, Part 20: Licensing of Production and Utilization Facilities, Washington, D.C., January 1, 1987. 
Table 2

Injection - Election Model Results

$\begin{array}{cccc}\text { Reactor Power } & \text { Temo. Coeff } & \text { Delay Time } & \text { Peak Power } \\ 5 \mathrm{MW} & -3.83 \times 10^{4} & 50 \mathrm{msec} & 102 \% \\ 5 \mathrm{MW} & -3.83 \times 10^{4} & 150 \mathrm{msec} & 103 \% \\ 5 \mathrm{MW} & -3.83 \times 10^{4} & 350 \mathrm{msec} & 103 \% \\ 5 \mathrm{MW} & -3.83 \times 10^{4} & 550 \mathrm{msec} & 101 \% \\ 5 \mathrm{MW} & -3.83 \times 10^{4} & 750 \mathrm{msec} & 98 \% \\ 5 \mathrm{MW} & -3.83 \times 10^{4} & 950 \mathrm{msec} & 96 \% \\ 5 \mathrm{MW} & -1.00 \times 10^{3} & 50 \mathrm{msec} & 112 \% \\ 5 \mathrm{MW} & -1.00 \times 10^{3} & 950 \mathrm{msec} & 125 \% \\ & & \text { Täble } 3 & \end{array}$

Fuel Temperature Coefficient Reactivity Effects

$\begin{array}{crc}\text { Euel Temperature } & \text { Keff Value } \\ 71^{\circ} \mathrm{C} & 1.21256 & \\ 90^{\circ} \mathrm{C} & 1.21255 & \mathrm{w} / \mathrm{U}-238 \\ 200^{\circ} \mathrm{C} & 1.21250 & \\ & & \\ 71^{\circ} \mathrm{C} & 1.23300 & \mathrm{w} / \mathrm{O} \mathrm{U}-238 \\ 200^{\circ} \mathrm{C} & 1.23296 & \end{array}$


Table 4

NORMALIZED SPACE-TIME CORE BEHAVIOR-LOSS OF He-3 AFTER INJECTION |

FUEL ASSEMBLY IDENTIFICATION MAP

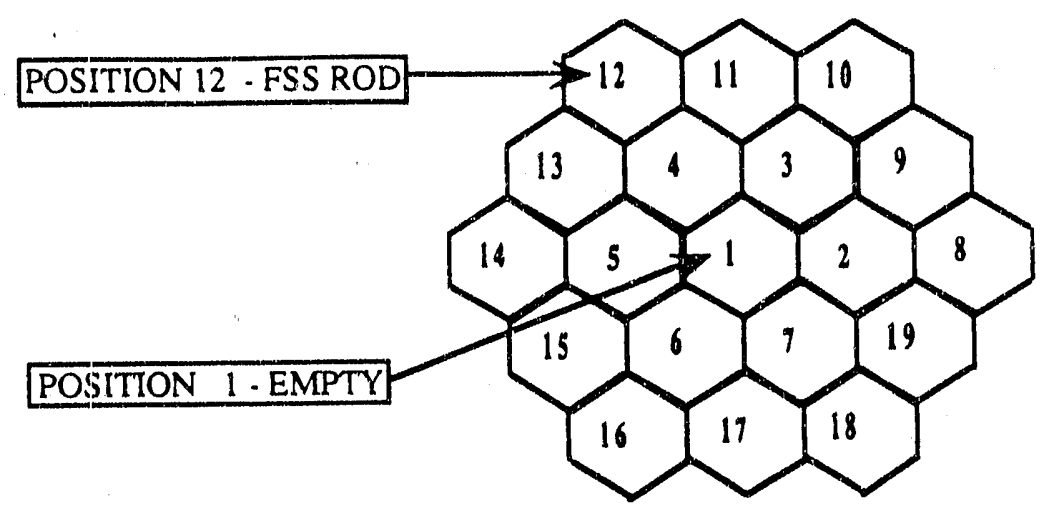

\begin{tabular}{|c|c|c|c|c|c|c|c|c|c|c|}
\hline & \multicolumn{10}{|c|}{ *** HEX POSITION *** } \\
\hline $\begin{array}{c}\text { Time } \\
(\mathrm{msec})\end{array}$ & $\begin{array}{c}\text { GLOBAL } \\
\text { POWER } \\
(\mathrm{AA} 3)\end{array}$ & 2 & 3 & 4 & 5 & 6 & 7 & 8 & 9 & 10 \\
\hline 0 & 1.000 & 1.000 & 1.000 & 1.000 & 1.000 & 1.000 & 1.000 & 1.000 & 1.000 & 1.000 \\
\hline 5 & 0.951 & 0.959 & 0.947 & 0.925 & 0.947 & 0.959 & 0.962 & 0.963 & 0.956 & 0.945 \\
\hline 10 & 0.842 & 0.854 & 0.838 & 0.806 & 0.838 & 0.854 & 0.859 & 0.860 & 0.850 & 0.834 \\
\hline 15 & 0.725 & 0.738 & 0.720 & 0.686 & 0.720 & 0.738 & 0.743 & 0.744 & 0.734 & 0.716 \\
\hline 20 & 0.620 & 0.633 & 0.615 & 0.582 & 0.615 & 0.633 & 0.638 & 0.639 & 0.629 & 0.611 \\
\hline 25 & 0.536 & 0.547 & 0.531 & 0.499 & 0.531 & 0.547 & 0.552 & 0.553 & 0.544 & 0.527 \\
\hline 30 & 0.470 & 0.481 & 0.466 & 0.436 & 0.466 & 0.481 & 0.486 & 0.487 & 0.478 & 0.462 \\
\hline 40 & 0.385 & 0.395 & 0.381 & 0.355 & 0.381 & 0.395 & 0.399 & 0.400 & 0.392 & 0.378 \\
\hline 50 & 0.340 & 0.349 & 0.336 & 0.312 & 0.336 & 0.349 & 0.353 & 0.354 & 0.346 & 0.333 \\
\hline 70 & 0.310 & 0.319 & 0.306 & 0.284 & 0.306 & 0.319 & 0.322 & 0.323 & 0.316 & $0.3 \cap 4$ \\
\hline 100 & 0.304 & 0.312 & 0.300 & 0.279 & 0.300 & 0.312 & 0.316 & 0.316 & 0.310 & 0.298 \\
\hline 120 & 0.319 & 0.326 & 0.315 & 0.296 & 0.315 & 0.326 & 0.329 & 0.330 & 0.324 & 0.313 \\
\hline 140 & 0.429 & 0.435 & 0.426 & 0.410 & 0.426 & 0.435 & 0.437 & 0.437 & 0.433 & 0.424 \\
\hline 150 & 0.548 & 0.548 & 0.548 & 0.548 & 0.548 & 0.548 & 0.548 & 0.548 & 0.548 & 0.548 \\
\hline 175 & 0.786 & 0.786 & 0.786 & 0.786 & 0.786 & 0.786 & 0.786 & 0.786 & 0.786 & 0.786 \\
\hline 200 & 0.907 & 0.907 & 0.907 & 0.907 & 0.907 & 0.907 & 0.907 & 0.907 & 0.907 & 0.907 \\
\hline 250 & 1.003 & 1.003 & 1.003 & 1.003 & 1.003 & 1.003 & 1.003 & 1.003 & 1.003 & 1.003 \\
\hline 300 & 1.026 & 1.026 & 1.026 & 1.026 & 1.026 & 1.026 & 1.026 & 1.026 & 1.026 & 1.026 \\
\hline 320 & 1.027 & 1.027 & 1.027 & 1.027 & 1.027 & $1.02 \%$ & 1.027 & 1.027 & 1.027 & 1.027 \\
\hline 350 & i. 0200 & 1.026 & 1.026 & 1.026 & 1.026 & 1.026 & 1.026 & 1.026 & 1.026 & 1.026 \\
\hline 1000 & 0.986 & 0.986 & 0.986 & 0.986 & 0.986 & 0.986 & 0.986 & 0.986 & 0.986 & 0.986 \\
\hline
\end{tabular}


Table 4 (Cont'd)

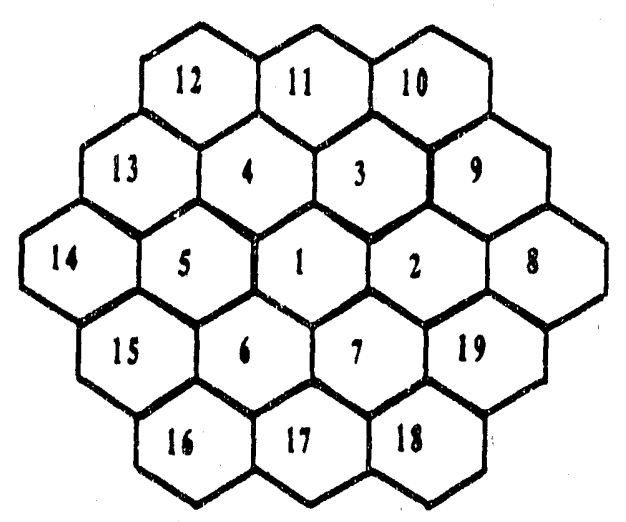

\begin{tabular}{|c|c|c|c|c|c|c|c|c|c|}
\hline \multicolumn{1}{c|}{} & \multicolumn{10}{|c|}{ *** HEX POSITION *** } \\
\hline $\begin{array}{c}\text { Time } \\
\text { (msec) }\end{array}$ & $\begin{array}{c}\text { GLOBAL } \\
\text { POWER }\end{array}$ & 11 & 13 & 14 & 15 & 16 & 17 & 18 & 19 \\
\hline 0 & 1.000 & 1.000 & 1.000 & 1.000 & 1.000 & 1.000 & 1.000 & 1.000 & 1.000 \\
\hline 5 & 0.951 & 0.917 & 0.917 & 0.945 & 0.956 & 0.963 & 0.966 & 0.968 & 0.966 \\
\hline 10 & 0.842 & 0.794 & 0.794 & 0.834 & 0.850 & 0.860 & 0.864 & 0.866 & 0.864 \\
\hline 15 & 0.725 & 0.672 & 0.672 & 0.716 & 0.734 & 0.744 & 0.748 & 0.751 & 0.748 \\
\hline 20 & 0.620 & 0.569 & 0.569 & 0.611 & 0.629 & 0.639 & 0.644 & 0.646 & 0.644 \\
\hline 25 & 0.536 & 0.487 & 0.487 & 0.527 & 0.544 & 0.553 & 0.557 & 0.560 & 0.557 \\
\hline 30 & 0.470 & 0.424 & 0.424 & 0.462 & 0.478 & 0.487 & 0.491 & 0.493 & 0.491 \\
\hline 40 & 0.385 & 0.344 & 0.344 & 0.378 & 0.392 & 0.400 & 0.404 & 0.406 & 0.404 \\
\hline 50 & 0.340 & 0.302 & 0.302 & 0.333 & 0.346 & 0.354 & 0.357 & 0.359 & 0.357 \\
\hline 70 & 0.310 & 0.275 & 0.275 & 0.304 & 0.316 & 0.323 & 0.326 & 0.328 & 0.326 \\
\hline 100 & 0.304 & 0.270 & 0.270 & 0.298 & 0.310 & 0.316 & 0.319 & 0.321 & 0.319 \\
\hline 120 & 0.319 & 0.287 & 0.287 & 0.313 & 0.324 & 0.330 & 0.332 & 0.334 & 0.332 \\
\hline 140 & 0.429 & 0.404 & 0.404 & 0.424 & 0.433 & 0.438 & 0.440 & 0.441 & 0.440 \\
\hline 150 & 0.548 & 0.548 & 0.548 & 0.548 & 0.548 & 0.548 & 0.548 & 0.548 & 0.548 \\
\hline 175 & 0.786 & 0.786 & 0.786 & 0.786 & 0.786 & 0.786 & 0.786 & 0.786 & 0.786 \\
\hline 200 & 0.907 & 0.907 & 0.907 & 0.907 & 0.907 & 0.907 & 0.907 & 0.907 & 0.907 \\
\hline 250 & 1.003 & 1.003 & 1.003 & 1.003 & 1.003 & 1.003 & 1.003 & 1.003 & 1.003 \\
\hline 300 & 1.026 & 1.026 & 1.026 & 1.026 & 1.026 & 1.026 & 1.026 & 1.026 & 1.026 \\
\hline 320 & 1.027 & 1.027 & 1.027 & 1.027 & 1.027 & 1.027 & 1.027 & 1.027 & 1.027 \\
\hline 350 & 1.026 & 1.026 & 1.026 & 1.026 & 1.026 & 1.026 & 1.026 & 1.026 & 1.026 \\
\hline 1000 & 0.986 & 0.986 & 0.986 & 0.986 & 0.986 & 0.986 & 0.986 & 0.986 & 0.986 \\
\hline & & & & 16 & & & & & \\
\hline
\end{tabular}


Figure 5

Injection-Ejection Power Transient

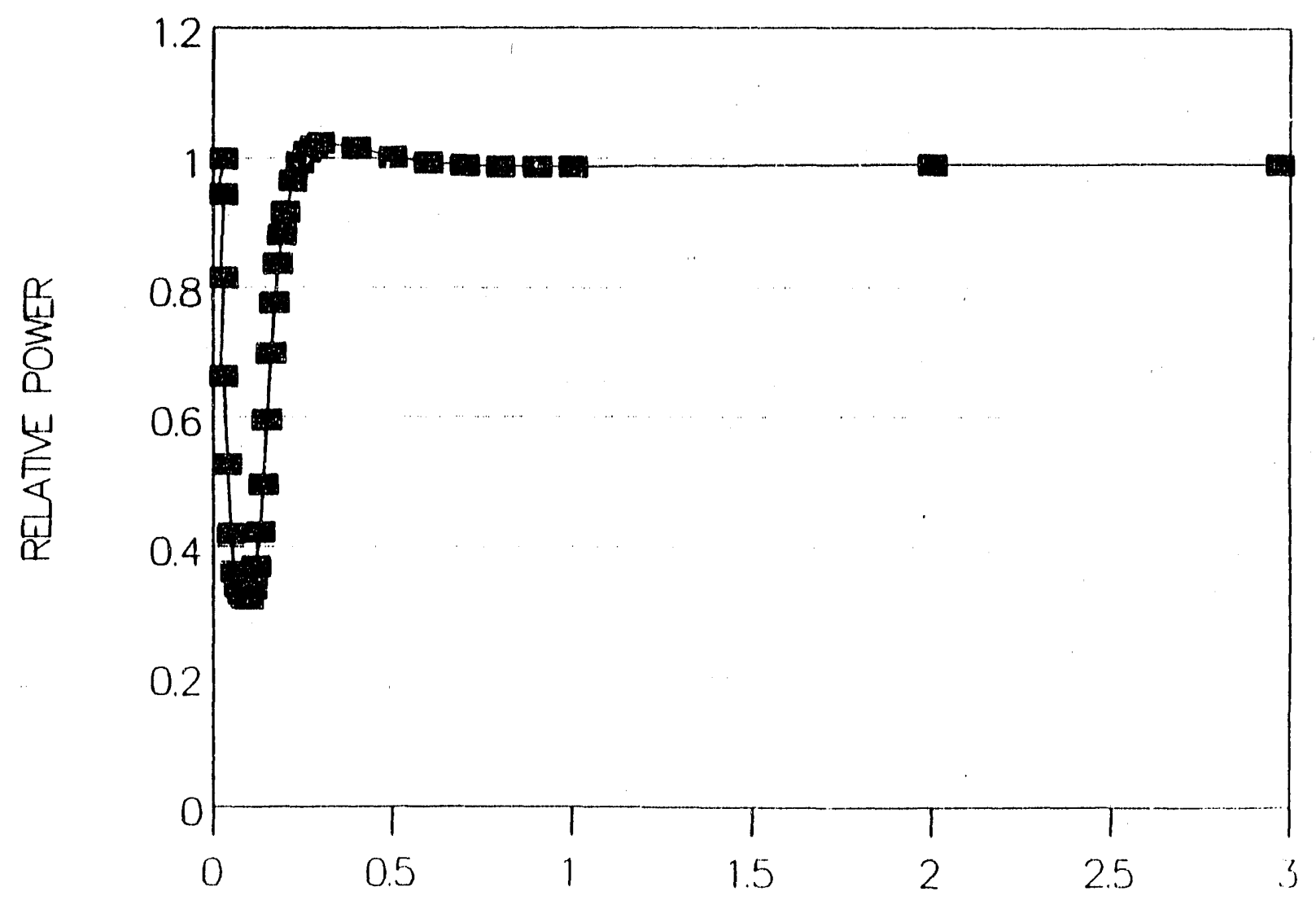

TIMF, seconds 

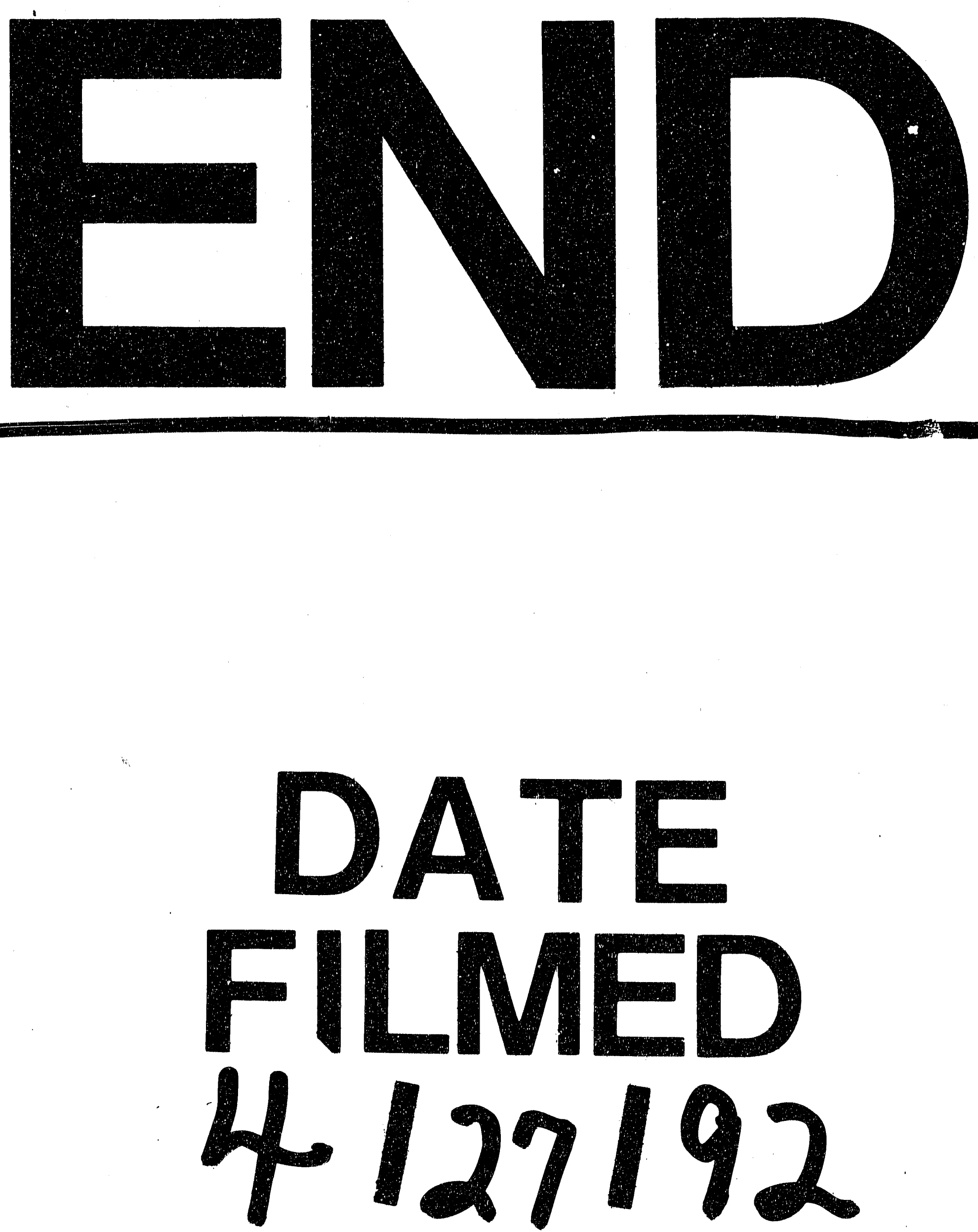

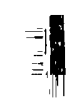


